\title{
ОЦЕНКА ЭФФЕКТИВНОСТИ УПРАВЛЕНИЯ ГОСУДАРСТВЕННЫМ ИМУЩЕСТВОМ: КРИТЕРИИ И ПОКАЗАТЕЛИ РЕЗУЛЬТАТИВНОСТИ 1
}

\section{EVALUATION OF THE EFFECTIVENESS OF STATE PROPERTY MANAGEMENT: CRITERIA AND PERFORMANCE INDICATORS}

O. Pivovarova

Summary. The article considers the features of organizing and evaluating the effectiveness of public civil servants at the regional level on the example of the Lipetsk region. The structure of public civil servant's salary is analyzed. It is revealed that its main parts depend on the position, rank and seniority. The system of evaluating the effectiveness and efficiency of professional service activities of a public civil servant is considered, features and disadvantages are highlighted. The directions for improving the structure of the monetary content of public civil servants, evaluating the effectiveness of their activities, the mechanism of responsibility and the system of non-material incentives are offered.

Keywords: activities of public civil servants, socio-economic development of the region, efficiency assessment, incentive system, management, responsibility.
$\Pi$ роблема осуществления эффективного управления государственным имуществом на разных уровнях власти в России является актуальной на протяжении уже не одного десятилетия, однако в качестве ключевого управленческого инструмента в этой сфере применяется приватизация, что, с одной стороны, является отражением политики разгосударствления собственности в целом, а с другой - следствием имеющихся недостатков в области оценки эффективности деятельности государственных предприятий и организаций.

Однако указанные недостатки нарушают целевое начало управления государственным имуществом в целом, суть которого заключается в обеспечении оптимального, при имеющихся ресурсах государственной собственности, удовлетворения потребностей населе-
Пивоварова Ольга Владимировна

Заместитель директора Института региональной экономики и межбюджетных отношений, Финансовый университет при Правительстве Российской Федерачии (г. Москва) olga_piv@mail.ru

Аннотация. В статье рассмотрена проблема оценки эффективности управления государственным имуществом, представлена ее специфика на различных уровнях власти и проведен анализ существующих методик оценки. Предложены и охарактеризованы критерии эффективности для проведения оценки управления государственным имуществом: общеэкономический (финансовая и бюджетная эффективность), управленческий, системно-функциональный, социальный, национальный (общественный), институциональный. В соответствии с выделенными критериями сформирован набор показателей для проведения оценки эффективности деятельности государственных предприятий. Определены диапазоны балльно-рейтинговых значений для предложенных показателей в соответствии со спецификой разделов.

Ключевые слова: государственное имущество, приватизация, оценка эффективности, критерии, показатели результативности, государственные предприятия.

ния в общественных благах и выполнении задач и функций государства, отвечающих требованиям времени, что зачастую приводит к приватизации общественно важных, а иногда и стратегических, объектов собственности, что обусловлено не социально-экономическим, а политическим характером приватизации, осуществляемой стихийно без существенного экономического и социального обоснования.

Так, например, в России активно приватизируются предприятия ТЭК, химической и металлургической промышленности, объекты системы здравоохранения, аэропорты, порты, а также научно-исследовательские институты, деятельность которых связана с обороноспособностью страны. Преобразование посредством приватизации в ОАО «Информационные спутниковые 
системы» имени академика М.Ф. Решетнёва» ФГУП «Научно-производственное объединение прикладной механики имени академика М.Ф. Решетнёва», деятельность которого связана с разработкой навигационных приборов и спутников связи, в результате привело к тому, что теперь Россия вынуждена арендовать каналы связи у других стран [1, С. 69]. В Липецкой области приватизации подверглись такие социально значимые объекты как: ОАО «Липецк-медтехника», ГУП «Липецкое», объекты газоснабжения, здание фельдшерско-акушерского пункта [2]. Несмотря на стратегическую и общественную значимость данных объектов собственности мнение экспертного и гражданского сообщества при принятии соответствующих решений учтено не было.

Данная ситуация имеет место, во многом, из-за отсутствия единой системы оценки эффективности и результативности в сфере управления государственным имуществом в целом и государственными предприятиями в частности, а также излишнего сосредоточения на финансовых показателях эффективности, что не всегда объективно в отношении стратегически и социально значимых объектов собственности [3, С. 304].

Большинство существующих методик сосредоточены либо на оценке коммерческой, либо бюджетной эффективности. В отношении государственных предприятий в качестве ключевых показателей эффективности определены такие как: выручка от продажи товаров, продукции, работ, услуг (за вычетом НДС, акцизов и других обязательных платежей); чистая прибыль (убыток); чистые активы; часть прибыли, подлежащая перечислению в бюджеты различных уровней [4, С. 1133]. Данные индикаторы фактически дублируют показатели эффективности частных предприятий, отличаясь лишь ориентиром на выполнение фискальной функции, в то время как остальные эффекты от деятельности государственных предприятий оценке не подвергаются.

Бюджетный аспект в наибольшей степени отражен в методике Т.Ю. Лушниковой и А.М. Ахматовой, которые определяют эффективность использования государственной собственности как соотношение полученных бюджетом доходных поступлений к затратам на управление [5, С. 25]:

$$
\ni_{э к}=\frac{Д_{u c n}+H_{\partial}+\Pi_{p}}{3},
$$

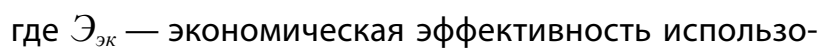
вания государственной собственности;

$Д_{u c n}$ - совокупные доходы от аренды и приватизации объектов государственной собственности, руб.;

$H_{\partial}$ - налоговые поступления от государственной собственности в бюджет соответствующего уровня, руб.;
$\Pi_{p}$ - поступления в бюджет соответствующего уровня доходов от перечисления части прибыли государственных предприятий, руб.;

3 - общие затраты на управление госсобственностью, руб.

Несмотря на наличие и других методик оценки эффективности управления государственным имуществом, следует отметить, что и в них не отражаются иные аспекты эффективности, в то время как данная категория является многоаспектной и в контексте удовлетворения общественных потребностей приобретает особое значение [6, С. 37]. В этой связи представляется целесообразным выделить критерии эффективности, в соответствии с которыми должны строиться соответствующие методики оценки.

В качестве первого критерия следует выделить общеэкономический критерий эффективности, который отражает соотношение между затратами и результатами различными способами и представлен двумя составляющими в сфере управления государственным имуществом - финансовой и бюджетной эффективностью. Именно данному критерию соответствует большинство существующих методик.

Финансовая эффективность заключается в оценке результатов финансово-хозяйственной деятельности предприятия и предполагает применение показателей из коммерческой сферы, о которых упоминалось выше [7].

Бюджетная эффективность предполагает проведение оценки динамики поступающих от использования государственного имущества платежей в соответствующий бюджет.

Таким образом, общеэкономический критерий эффективности обеспечивает возможность проведения сравнений различающихся между собой систем по достигнутым результатам. Однако, можно подумать, что с позиции общеэкономического критерия расходы это такие, которые формируют доходы либо экономические выгоды, превышающие расходы. Такое представление справедливо при предположении о прямом управлении государственным имуществом и прямом извлечении выгод от его реализации в соответствующем периоде. Однако так бывает достаточно редко.

Например, выгоды от текущих общественных расходов и имущества могут распределяться не только на настоящее время, но и на будущее - тогда прямое сопоставление полученных явных выгод и издержек не характеризует полной экономической эффективности имущества. В условиях смешанной экономики общественные средства могут формировать выгоды 
Таблица 1. Показатели оценки эффективности деятельности государственных предприятий (продолжение на стр. 88)

\begin{tabular}{|c|c|c|c|}
\hline № & Показатель оценки эффективности & Значение показателя & $\begin{array}{l}\text { Оценка } \\
\text { по показателям } \\
\text { (в баллах) }\end{array}$ \\
\hline \multicolumn{4}{|c|}{ Финансовая эффективность } \\
\hline 1.1 & Выручка от реализации товаров и услуг & $\begin{array}{ll}\text { - } & \text { рост выручки; } \\
\text { - } & \text { выручка на уровне предыдущего года; } \\
\text { уменьшение выручки по отношению } \\
\text { к предыдущему году. }\end{array}$ & $\begin{array}{l}8-10 \\
4-7 \\
0-3\end{array}$ \\
\hline 1.2 & Чистая прибыль & $\begin{array}{l}\text { • } \quad \text { рост чистой прибыли; } \\
\text { чистая прибыль на уровне предыдущего } \\
\text { года. }\end{array}$ & $\begin{array}{l}7-10 \\
3-6\end{array}$ \\
\hline 1.3. & Коэффициент текущей ликвидности & $\begin{array}{l}\text { - } \quad \text { больше или равно 1,2; } \\
\text { - } \quad \text { менее 1,2, но больше или равно 1; } \\
\text { менее 1. }\end{array}$ & $\begin{array}{l}8-10 \\
4-7 \\
0-3\end{array}$ \\
\hline \multicolumn{4}{|c|}{ Бюджетная эффективность } \\
\hline 2.1 & $\begin{array}{l}\text { Прибыль, подлежащая перечислению в бюджет } \\
\text { за год }\end{array}$ & $\begin{array}{l}\text { - } \quad \text { составила 15\% и более от величины чистой } \\
\text { прибыли; } \\
\text { составила менее 15\% от величины чистой } \\
\text { прибыли. }\end{array}$ & $\begin{array}{l}7-10 \\
3-6\end{array}$ \\
\hline 2.2 & $\begin{array}{l}\text { Отношение доходов, зачисляемых в бюджет } \\
\text { от предприятия, к бюджетным расходам } \\
\text { на данное предприятие }\end{array}$ & $\begin{array}{l}\text { - } \quad \text { больше или равно 1,15; } \\
\text { - } \quad \text { менее 1,15, но больше или равно 1; } \\
\text { менее 1. }\end{array}$ & $\begin{array}{l}8-10 \\
4-7 \\
0-3\end{array}$ \\
\hline \multicolumn{4}{|c|}{ Управленческая эффективность } \\
\hline 3.1. & $\begin{array}{l}\text { Уникальность производимой продукции } \\
\text { (товаров и услуг) }\end{array}$ & $\begin{array}{ll}\text { • } & \text { продукция уникальна; } \\
\text { п } & \text { продукция не уникальна (существуют } \\
& \text { аналогичные товары и услуги) }\end{array}$ & $\begin{array}{l}10 \\
0\end{array}$ \\
\hline 3.2. & Влияние на рыночные цены в регионе & $\begin{array}{ll}\text { - } & \text { степень влияния высокая; } \\
\text { - } & \text { степень влияния средняя; } \\
\text { - } & \text { не влияет нла цены в регионе. }\end{array}$ & $\begin{array}{l}8-10 \\
4-7 \\
1-3 \\
0\end{array}$ \\
\hline 3.3. & $\begin{array}{l}\text { Инвестиционная привлекательность } \\
\text { (за исключением бюджетных инвестиций) }\end{array}$ & $\begin{array}{l}\text { • } \quad \text { привлечены инвестиции за последние } 3 \text { года; } \\
\text { не привлекались инвестиции за последние } \\
3 \text { года. }\end{array}$ & $\begin{array}{l}7-10 \\
0\end{array}$ \\
\hline 3.4 & $\begin{array}{l}\text { Доля экспортной продукции в общем объеме } \\
\text { производимой продукции за год }\end{array}$ & $\begin{array}{l}\text { - } \quad \text { составила } 20 \% \text { и более; } \\
\text { - } \quad \text { составила } 10 \% \text { и более, но менее 20\%; } \\
\text { - } \quad \text { отставила менее 10\%; } \\
\text { осстует экспортная продукция. }\end{array}$ & $\begin{array}{l}8-10 \\
4-7 \\
1-3 \\
0\end{array}$ \\
\hline \multicolumn{4}{|c|}{ Системно-функциональная эффективность } \\
\hline 4.1. & $\begin{array}{l}\text { Предприятие использует продукцию других } \\
\text { предприятий и организаций в регионе }\end{array}$ & 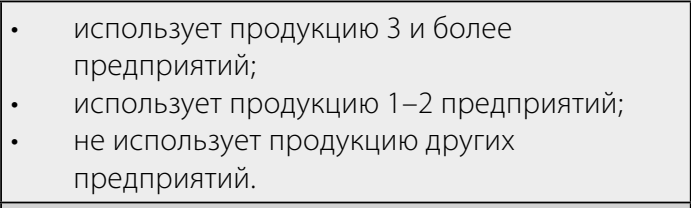 & $\begin{array}{l}7-10 \\
3-6 \\
0\end{array}$ \\
\hline 4.2 & $\begin{array}{l}\text { Предприятие поставляет продукцию (товары } \\
\text { и услуги) для других предприятий в регионе }\end{array}$ & $\begin{array}{ll}\text { • } & \text { поставляет продукцию для } 3 \text { и более } \\
\text { • } & \text { предприятий; } \\
\text { • } & \text { неставляет продукцию для } 1-2 \text { предприятий; } \\
& \text { предприятий. }\end{array}$ & $\begin{array}{l}7-10 \\
3-6 \\
0\end{array}$ \\
\hline 4.3. & $\begin{array}{l}\text { Влияние на состояние окружающей среды } \\
\text { в регионе }\end{array}$ & 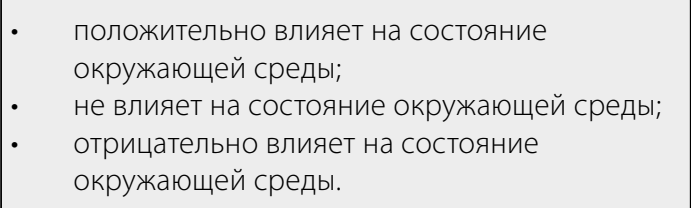 & $\begin{array}{l}7-10 \\
3-6 \\
0\end{array}$ \\
\hline
\end{tabular}


Таблица 1. Показатели оценки эффективности деятельности государственных предприятий (продолжение)

\begin{tabular}{|c|c|c|c|}
\hline № & Показатель оценки эффективности & Значение показателя & $\begin{array}{l}\text { Оценка } \\
\text { по показателям } \\
\text { (в баллах) }\end{array}$ \\
\hline \multicolumn{4}{|c|}{ Социальная эффективность } \\
\hline 5.1. & Численность персонала предприятия за год & $\begin{array}{ll}\text { • } & \text { увеличилась; } \\
\text { • } & \text { осталась на прежнем уровне; } \\
\text { • } & \text { уменьшилась }\end{array}$ & $\begin{array}{l}8-10 \\
5 \\
0\end{array}$ \\
\hline 5.2 & $\begin{array}{l}\text { Средняя заработная плата работников } \\
\text { (рассчитанная за исключением заработной } \\
\text { платы руководящего состава) }\end{array}$ & $\begin{array}{l}\text { - } \quad \text { выше средней заработной платы по региону } \\
\text { более, чем на 20\%; } \\
\text { выше средней заработной платы по региону } \\
\text { более, чем на 10\%, но менее, чем на 20\%; } \\
\text { выше средней заработной платы по региону } \\
\text { менее, чем на 10\%; } \\
\text { - } \quad \text { ниже средней заработной платы по региону. }\end{array}$ & $\begin{array}{l}8-10 \\
4-7 \\
1-3 \\
0\end{array}$ \\
\hline 5.3. & $\begin{array}{l}\text { Востребованность производимых товаров } \\
\text { и услуг населением региона (на основе } \\
\text { динамики потребления) }\end{array}$ & $\begin{array}{ll}\text { • } & \text { потребление продукции выше, чем } \\
\text { в предыдущем году; } \\
\text { потребление продукции на уровне } \\
\text { предыдущего года; } \\
\text { • } \\
\text { потребление продукции ниже уровня } \\
\text { предыдущего года. }\end{array}$ & $\begin{array}{l}7-10 \\
3-6 \\
0\end{array}$ \\
\hline 5.4 & Социальная значимость продукции & $\begin{array}{ll}\text { - } & \text { высокая степень значимости; } \\
\text { • } & \text { средняя степень значимости; } \\
\text { • } & \text { низкая степень значимости. }\end{array}$ & $\begin{array}{l}8-10 \\
4-7 \\
0-3\end{array}$ \\
\hline \multicolumn{4}{|c|}{ Институциональная эффективность } \\
\hline 6.1. & $\begin{array}{l}\text { Отношение доходов, полученных от продажи } \\
\text { предприятия, к трансакционным издержкам } \\
\text { в результате изменения его формы } \\
\text { собственности }\end{array}$ & $\begin{array}{ll}\text { - } & \text { меньше или равно 1; } \\
\text { · } & \text { больше 1, но меньше 3; } \\
\text { • } & \text { больше или равно } 3 .\end{array}$ & $\begin{array}{l}8-10 \\
4-7 \\
0-3\end{array}$ \\
\hline 6.2 & $\begin{array}{l}\text { Отношение трансакционных издержек } \\
\text { в результате изменения формы собственности } \\
\text { предприятия к доходам, подлежащим } \\
\text { зачислению в бюджет за предыдущий год }\end{array}$ & $\begin{array}{l}\text { - } \quad \text { больше 1; } \\
\text { - } \quad \text { меньше 1, но больше 0,5; } \\
\text { меньше 0,5. }\end{array}$ & $\begin{array}{l}8-10 \\
4-7 \\
0-3\end{array}$ \\
\hline \multicolumn{4}{|c|}{ Национальная (общественная) эффективность } \\
\hline 7.1. & $\begin{array}{l}\text { Согласие трудового коллектива } \\
\text { на приватизацию предприятия }\end{array}$ & $\begin{array}{l}\text { - } \quad \text { согласие выразили менее 30\% коллектива; } \\
\text { с согласие выразили более } 30 \% \text { коллектива, } \\
\text { но менее 60\%; } \\
\text { • } \quad \text { согласие выразили более } 60 \% \text { коллектива. }\end{array}$ & $\begin{array}{l}8-10 \\
4-7 \\
0-3\end{array}$ \\
\hline 7.2 & $\begin{array}{l}\text { Согласие общественности (профильных } \\
\text { общественных советов и объединений) } \\
\text { на приватизацию предприятия }\end{array}$ & $\begin{array}{l}\text { - } \quad \text { согласие выразили менее 30\%; } \\
\text { · } \quad \text { согласие выразили более 30\%, но менее 50\%; } \\
\text { согласие выразили более 50\%. }\end{array}$ & $\begin{array}{l}8-10 \\
4-7 \\
0-3\end{array}$ \\
\hline 7.3. & $\begin{array}{l}\text { Общественная оценка эффективности } \\
\text { деятельности предприятия посредством } \\
\text { опроса на интернет-платформах }\end{array}$ & 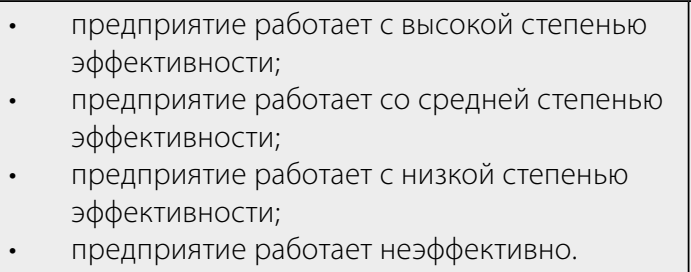 & $\begin{array}{l}8-10 \\
4-7 \\
1-3 \\
0\end{array}$ \\
\hline
\end{tabular}

не только в общественном, но и в рыночном секторе экономики. Но тогда расходы необходимо сопоставлять с выгодами, полученными в обоих секторах [8, C. 104]. Учитывая множество возможных альтернатив использования общественных средств, не всякие расходы, обеспечивающие превышение доходов над ними, следует считать эффективными, а лишь такие, которые в пределах наличных ограничений их общей суммы, реализуют набор наилучших альтернатив - в порядке убывания их предельной эффективности, обеспечивая в итоге наилучшее соотношение между полученными суммарными полезными эффектами произведенных расходов и их общей суммой [9]. Именно такое управление государственным имуществом следует признать 
эффективным, поскольку оно обеспечивает повышение уровня совокупного благосостояния населения.

Кроме того, помимо отсутствия возможности проведения адекватной денежной оценки многие действия имеют отложенный и вероятностный характер. При этом данные эффекты нельзя недооценивать, что обуславливает необходимость применения дополнительных критериев эффективности.

Оценить стратегическую значимость государственного имущества, например, конкретного предприятия, для развития территории и страны в целом, с учетом инвестиционной привлекательности и экспортного потенциала позволяет управленческий критерий эффективности.

Непосредственно связан с ним критерий системно-функциональной эффективности, предполагающий оценку воздействия и взаимосвязи государственного предприятия с другими организациями региона, а также косвенных эффектов от его деятельности. Практическая реализация данного критерия позволяет нивелировать негативное воздействие для связанных организаций при принятии решений в отношении государственного имущества.

Целевая направленность на удовлетворение общественных потребностей процесса управления государственным имуществом должна находить отражение в критерии социальной эффективности, который позволяет проанализировать социальную значимость объекта государственной собственности, а также, в случае, когда это предприятие, производимых им товаров и услуг [10, С. 20].

Непосредственно связан с социальным критерий национальной (общественной) эффективности, предполагающий необходимость учета мнения населения и общественных организаций по приватизации конкретного объекта, а также согласие трудового коллектива и региональных органов власти с учетом специфики [11, С. 69].

При принятии управленческих решений в отношении трансформации формы собственности государственного предприятия или иного объекта имущества также необходимо оценивать трансакционные издержки и прочие затраты, возникающие при этом, что находит отражение в институциональной эффективности [12].

Анализ имущества по предложенным критериям позволит осуществлять комплексную оценку деятельности объектов государственной собственности и определить, что эффективнее развивать в рамках государственной собственности, а что принесет больше пользы в рыночном секторе.
Предлагается следующий набор показателей для оценки государственных предприятий в разрезе критериев эффективности, представленный в таблице 1.

Если результирующая оценка по всем критериям равна или выше 165 баллов, деятельность предприятия эффективна, его можно отнести к стабильно развивающимся. Если оценка по всем критериям составляет от 45 до 165 баллов, деятельность предприятия удовлетворительна, оно относится к стабильно работающим. Если же оценка ниже 45 баллов, деятельность предприятия неэффективна, оно считается неудовлетворительно работающим, а, значит, должно быть приватизировано в первую очередь.

Несмотря на балльный характер оценки она содержит достаточное число как качественных, так и количественных индикаторов, что свидетельствует о довольно высоком уровне ее объективности и подтверждает целесообразность применения. Более того, такой подход позволяет проводить сравнения различных по масштабам и специфике деятельности государственных предприятий.

Таким образом, результаты оценки позволяют получить комплексное представление о деятельности объекта государственного имущества и принять целесообразное управленческое решение об изменении его формы собственности. При этом особого внимания заслуживает группа предприятий, чья деятельность оценивается как удовлетворительная. В этом случае необходимо отдельно проанализировать те критерии эффективности, по которым получены наименьшие баллы с тем, чтобы выработать меры по совершенствованию данных направлений. Если же при последующей оценке данные критерии снова окажутся на низком уровне, то целесообразно рассмотреть вопрос о структурных изменениях данного предприятия, в том числе о частичной приватизации. Более того, часть данных критериев и показателей следует использовать и в постприватизационной оценке, что позволит проанализировать, устранены ли существующие проблемы и стало ли предприятие в действительности более эффективно осуществлять свою деятельность.

Представляется, что предложенные критерии эффективности управления государственным имуществом, а также разработанные в соответствии с ними показатели оценки эффективности деятельности государственных предприятий позволят обеспечить комплексный подход при принятии управленческих решений, не допустить разгосударствления принципиально важных объектов собственности и повысить эффективность использования государственного имущества в целом. 


\section{ЛИТЕРАТУРА}

1. Пивоварова 0.В. Механизм реализации общественной собственности как основа эффективного управления государственным имуществом: проблемы формирования и пути развития // Государственное и муниципальное управление. Ученые записки. 2019. № 3. С. 66-73.

2. 06 итогах программы социально-экономического развития Липецкой области на 2013-2017 гг. за 2013-2015 гг. [Электронный ресурс] // URL: http:// www.oblsovet.ru/legislation/bill/12299/

3. Bykova 0.N., Stroev P.V., Morkovkin D.E., Kurbakova S.N., Repnikova V.M. Improvement of approaches to the strategic development management of enterprise // Entrepreneurship and Sustainability Issues. 2020. T. 8. № 1. C. 301-312.

4. Пивоварова 0.В. К вопросу об оценке эффективности управления государственным имуществом // Научно-методический электронный журнал Концепт. 2017. № Т31. С. 1131-1135.

5. Лушникова Т.Ю., Ахматова А.М. 06 оценке эффективности управления муниципальным имуществом // Вестник Челябинского государственного университета. 2015. № 1 (356). Управление. Вып. 10. С. 22-30.

6. Соловьев М.М., Кошкин Л.И. Проблемы оценки эффективности управления государственной собственностью // Менеджмент в России и за рубежом. 2008. № 4. C. 32-46.

7. Кошкин Л.И., Соловьев М.М. Управление недвижимым имуществом: эффективность и результативность // Управление. 2004.

8. Фаттахов Р.В., Низамутдинов М.М., Орешников В.В. Инструментарий обоснования параметров стратегического развития региона на базе адаптивно-имитационного моделирования // Регион: Экономика и Социология. 2017. № 1 (93). С. 101-120.

9. Лаптев С.В. Основы теории государственных финансов / С.В. Лаптев // учебное пособие для студентов, обучающихся по специальностям «Финансы и кредит», «Бухгалтерский учет, анализ и аудит», «Мировая экономика»: учебное пособие для студентов высших учебных заведений, обучающихся по направлениям экономики и управления / С.В. Лаптев. Москва, 2010. (2-е изд., перераб. и доп.)

10. Маркварт Э. Эффективность управления публичной собственностью: понятие, подходы, критерии // Проблемы теории и практики управления. 2014. № 6. C. 17-26.

11. Макар С.В., Симагин Ю.А., Ярашева А.В. Демографическая ситуация в России и социальная инфраструктура // Народонаселение. 2020. Т. 23. № 1. C. 67-75.

12. Олейник А.Н. Институциональная экономика: Учеб. пособие. — М.: ИНФРА-М, 2009.

(c) Пивоварова Ольга Владимировна ( olga_piv@mail.ru ).

Журнал «Современная наука: актуальные проблемы теории и практики»

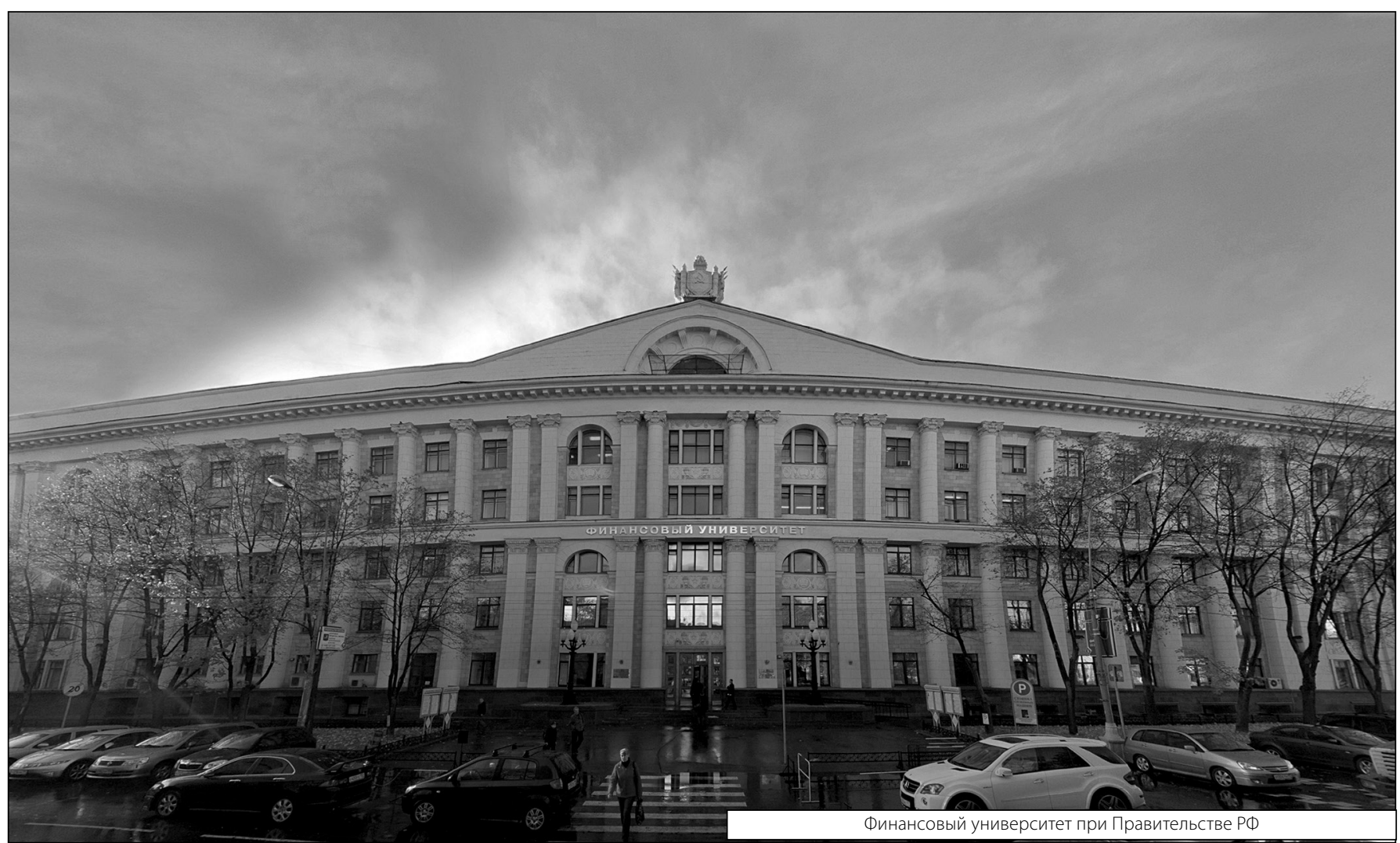

